Atmos. Chem. Phys., 17, 10259-10268, 2017

https://doi.org/10.5194/acp-17-10259-2017

(C) Author(s) 2017. This work is distributed under

the Creative Commons Attribution 3.0 License.

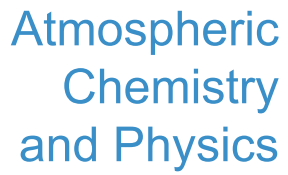

(c) (P)

\title{
Comparison of ozone profiles and influences from the tertiary ozone maximum in the night-to-day ratio above Switzerland
}

\author{
Lorena Moreira, Klemens Hocke, and Niklaus Kämpfer \\ Institute of Applied Physics and Oeschger Centre for Climate Change Research, University of Bern, Bern, Switzerland \\ Correspondence to: Lorena Moreira (lorena.moreira@iap.unibe.ch)
}

Received: 23 March 2017 - Discussion started: 28 March 2017

Revised: 30 June 2017 - Accepted: 8 August 2017 - Published: 1 September 2017

\begin{abstract}
Stratospheric and middle-mesospheric ozone profiles above Bern, Switzerland $\left(46.95^{\circ} \mathrm{N}, 7.44^{\circ} \mathrm{E} ; 577 \mathrm{~m}\right)$ have been continually measured by the GROMOS (GROundbased Millimeter-wave Ozone Spectrometer) microwave radiometer since 1994. GROMOS is part of the Network for the Detection of Atmospheric Composition Change (NDACC). A new version of the ozone profile retrievals has been developed with the aim of improving the altitude range of retrieval profiles. GROMOS profiles from this new retrieval version have been compared to coincident ozone profiles obtained by the satellite limb sounder Aura Microwave Limb Sounder (MLS). The study covers the stratosphere and middle mesosphere from 50 to $0.05 \mathrm{hPa}$ (from 21 to $70 \mathrm{~km}$ ) and extends over the period from July 2009 to November 2016, which results in more than 2800 coincident profiles available for the comparison. On average, GROMOS and MLS comparisons show agreement generally over $20 \%$ in the lower stratosphere and within $2 \%$ in the middle and upper stratosphere for both daytime and nighttime, whereas in the mesosphere the mean relative difference is below $40 \%$ during the daytime and below $15 \%$ during the nighttime. In addition, we have observed the annual variation in nighttime ozone in the middle mesosphere, at $0.05 \mathrm{hPa}(70 \mathrm{~km})$, characterized by the enhancement of ozone during wintertime for both ground-based and space-based measurements. This behaviour is related to the middle-mesospheric maximum in ozone (MMM).
\end{abstract}

\section{Introduction}

Passive millimetre wave radiometry is a well-established technique to monitor atmospheric constituents by detect- ing the radiation emitted by the rotational transitions of the molecules. It makes use of the spectral properties of the atmospheric species in order to derive information about their distribution in the atmosphere. The main advantages of this technique are its independence of solar irradiation and its insensitivity to weather conditions and aerosols. Additionally it offers a good temporal resolution of $1 \mathrm{~h}$. Measurements of ozone performed by this technique have been indispensable in monitoring changes in the ozone layer and improving the comprehension of the processes that control ozone abundances (e.g. Steinbrecht et al., 2009). Stratospheric ozone, in spite of its small abundance, plays a beneficial role by absorbing most of the biologically harmful ultraviolet sunlight. The absorption of UV radiation by ozone creates a source of heat; therefore, ozone plays a key role in the temperature structure of the Earth's atmosphere. Changes in the stratospheric ozone concentration alter the radiative balance of the atmosphere, the atmospheric composition and the dynamics of the atmosphere. Continuous long-term monitoring of ozone is essential for the detection of long-term trends in the stratospheric ozone layer (e.g. WMO, 2014). The ground-based ozone radiometer GROMOS (GROund-based Millimeter-wave Ozone Spectrometer) is part of the Network for the Detection of Atmospheric Composition Change (NDACC). In order to satisfy the requirements of accuracy and stability, the validation of instruments is necessary. There have been a number of comparisons in the past, showing that GROMOS is a reliable tool to measure stratospheric and lower-mesospheric ozone (WMO, 2014; Studer et al., 2013; van Gijsel et al., 2010; Keckhut et al., 2010; Dumitru et al., 2006)

This paper presents a comparison between the data from the ground-based instrument GROMOS and the space-based 
instrument Microwave Limb Sounder (MLS) for the time interval from July 2009 to November 2016 covering the stratosphere and the middle mesosphere, which corresponds to the altitude range of 20 to $70 \mathrm{~km}(50$ to $0.05 \mathrm{hPa})$. We have also performed an analysis of the diurnal variation and its amplitude (night-to-day ratio) of middle-mesospheric ozone at $0.05 \mathrm{hPa}(70 \mathrm{~km})$. The diurnal variation in ozone in the lower and middle mesosphere is observed as an increase in ozone after sunset and a decrease after sunrise. Daytime production of atomic oxygen by photolysis of ozone (Reaction R7) and photolysis of molecular oxygen (Reaction R5) results in nighttime ozone production by recombination of atomic and molecular oxygen (Reaction R6) (Brasseur and Solomon, 2005). In addition, we observe the annual variation in the nighttime mesospheric ozone with a maximum in wintertime and a minimum in summertime. This maximum in mesospheric ozone during nighttime in winter is related to the middle-mesospheric maximum in ozone (MMM) (e.g. Sonnemann et al., 2007; Hartogh et al., 2004) also known as the tertiary ozone maximum (e.g. Sofieva et al., 2009; Degenstein et al., 2005; Marsh et al., 2001). Sonnemann et al. (2007) reported that the MMM is a phenomenon that occurs at high latitudes close to the polar night terminator at around $72 \mathrm{~km}$ altitude during nighttime in winter and extends into middle latitudes with decreasing amplitude. Marsh et al. (2001) interpreted the tertiary peak by considering that in the middle mesosphere during winter, with a solar zenith angle close to $90^{\circ}$, the atmosphere becomes optically thick to UV radiation at wavelengths below $185 \mathrm{~nm}$, and, since photolysis of water vapour (Reaction R1) is the primary source of odd hydrogen, reduced UV radiation results in less odd hydrogen. The lack of odd hydrogen needed for the catalytic depletion of odd oxygen (Reactions R2, R3, and R4), in conjunction with an unchanged rate of odd-oxygen production (Reaction $\mathrm{R} 5)$, leads to an increase in odd oxygen. This results in higher ozone concentration because atomic oxygen recombination (Reaction R6) remains as a significant source of ozone in the mesosphere. Additionally, Hartogh et al. (2004) extended the interpretation by considering the very slow decrease in the ozone dissociation (Reaction R7) rate with increasing solar zenith angle.

$$
\begin{aligned}
& \mathrm{H}_{2} \mathrm{O}+\mathrm{h} v(\lambda<185 \mathrm{~nm}) \rightarrow \mathrm{OH}+\mathrm{O} \\
& \mathrm{O}+\mathrm{OH} \rightarrow \mathrm{O}_{2}+\mathrm{H} \\
& \mathrm{H}+\mathrm{O}_{2}+\mathrm{M} \rightarrow \mathrm{HO}_{2}+\mathrm{M} \\
& \mathrm{O}+\mathrm{HO}_{2} \rightarrow \mathrm{O}_{2}+\mathrm{OH} \\
& \mathrm{O}_{2}+\mathrm{h} v(\lambda<242 \mathrm{~nm}) \rightarrow \mathrm{O}+\mathrm{O} \\
& \mathrm{O}+\mathrm{O}_{2}+\mathrm{M} \rightarrow \mathrm{O}_{3}+\mathrm{M} \\
& \mathrm{O}_{3}+\mathrm{h} v \rightarrow \mathrm{O}_{2}+\mathrm{O}
\end{aligned}
$$

The next section describes briefly both instruments and measurement techniques. The results of the comparison are shown in Sect. 3. Section 4 analyses the night-to-day vari- ability and provides a short discussion, and the conclusions are summarized in Sect. 5.

\section{Instruments and measurement techniques}

\subsection{The ground-based microwave radiometer GROMOS}

This study is based on stratospheric and mesospheric ozone volume mixing ratio (VMR) profiles observed by GROMOS. The ground-based millimetre wave ozone spectrometer has been operating in Bern, Switzerland $\left(46.95^{\circ} \mathrm{N}\right.$, $7.44^{\circ} \mathrm{E} ; 577 \mathrm{~m}$ ) since November 1994 in the context of the Network for the Detection of Atmospheric Composition Change (NDACC). The instrument measures the thermal microwave emission of the pressure-broadened rotational transition of ozone at $142.175 \mathrm{GHz}$. The vertical distribution of the ozone VMR can be retrieved from the measured spectral line since it contains information on the altitude distribution of the emitting molecule due to the pressure broadening. The retrieval procedure is performed through the Atmospheric Radiative Transfer Simulator (ARTS2) (Eriksson et al., 2011) which is used as a forward model to simulate the atmospheric radiative transfer in a modelled atmosphere and so calculate the ozone spectrum of this modelled atmosphere. The a priori profile of $\mathrm{O}_{3} \mathrm{VMR}$ required for the retrieval is taken from a monthly varying climatology from ECMWF reanalysis as far as available $(70 \mathrm{~km})$ and extended above by an Aura MLS climatology (2004 to 2011). The line shape used in the retrieval is the representation of the Voigt line profile from Kuntz (1997). Spectroscopic parameters to calculate the ozone absorption coefficients were taken from the JPL catalogue (Pickett et al., 1998) and the HITRAN spectroscopic database (Rothman et al., 1998). The atmospheric temperature and pressure profiles are taken from the 6-hourly European Centre for Medium-Range Weather Forecast (ECMWF) operational analysis data and are extended above $80 \mathrm{~km}$ by monthly mean temperatures of the CIRA- 86 atmosphere model (Fleming et al., 1990). The accompanying Matlab package Qpack2 (Eriksson et al., 2005) compares the modelled spectrum with the measured spectrum and derives the best estimate of the vertical profile by using the optimal estimation method (OEM) (Rodgers, 1976). The OEM also provides a characterization and formal analysis of the uncertainties (Rodgers, 1990).

Recently, we have developed a new retrieval version (version 150) with the aim of optimizing the averaging kernels. The differences with the former version (version 2021) are in the a priori covariance matrix, in the measurement error, and in the integration time of the retrieval.

In version 2021 the diagonal elements of the a priori covariance matrix are variable relative errors ranging from $35 \%$ at $100 \mathrm{hPa}$ to $28 \%$ in the lower stratosphere and increasing with altitude from $35 \%$ in the upper stratosphere 


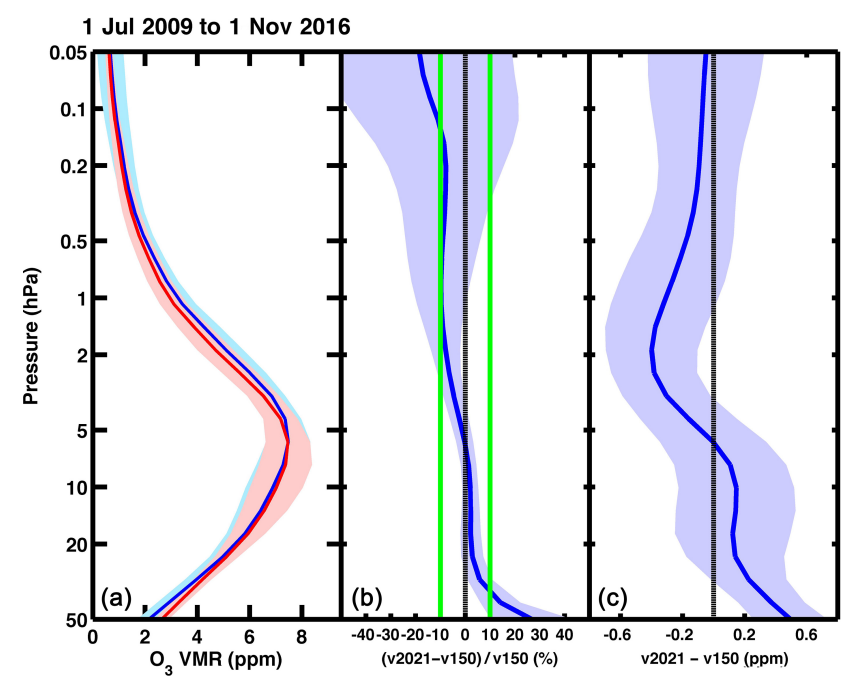

Figure 1. Mean ozone profiles retrieved by version 2021 (red line in panel (a)) and by version 150 (blue line in panel (a)) measured by GROMOS during the period from July 2009 to November 2016. The blue area (v150) and the red area (v2021) are the SDs of the ozone VMR. The mean relative difference profile (blue line) and the SD of the differences (blue area) are represented panel (b), using the new version as reference. The green line delimits the $\pm 10 \%$ area. The VMR difference profile along with its SD are shown in panel (c).

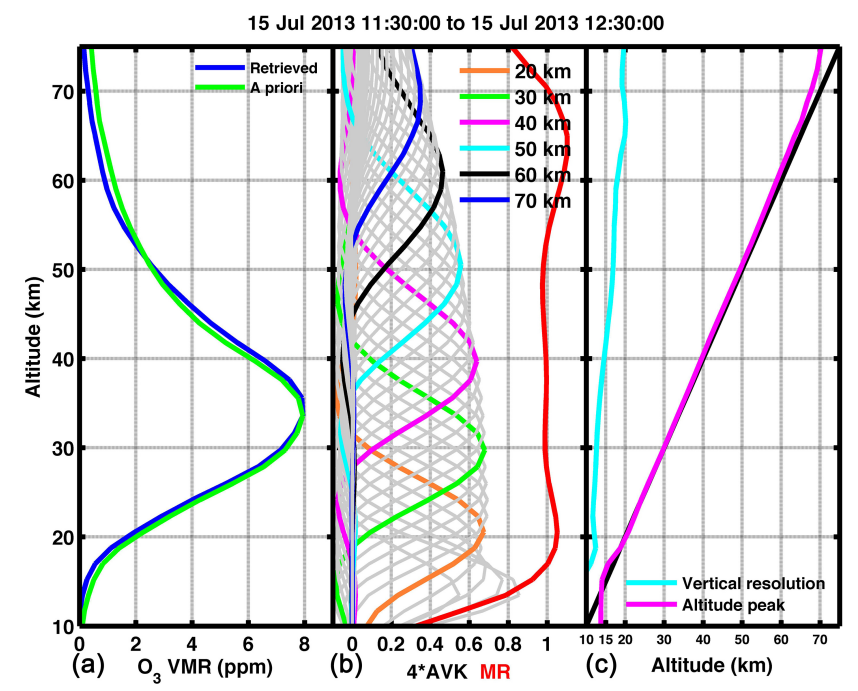

Figure 2. Example of an a priori profile and a retrieved ozone profile (green and blue lines in panel (a), respectively), averaging kernels (grey and coloured lines in panel (b)), the measurement response (red line in the panel), vertical resolution (cyan line in panel (c)), and altitude peak (magenta line in panel (c)) of the GROMOS retrieval version 150 for 15 July 2013 with an integration time of $1 \mathrm{~h}$.

up to $70 \%$ in the mesosphere. Meanwhile, in version 150 the a priori covariance matrix has a constant value for the diagonal elements of $2 \mathrm{ppm}$. For both retrieval versions the off-diagonal elements of the a priori covariance matrix exponentially decrease with a correlation length of $3 \mathrm{~km}$.

Regarding the measurement noise, in version 2021 it is a constant error of $0.8 \mathrm{~K}$, whereas in version 150 we used a variable error depending on the tropospheric transmission:

$\Delta T_{\mathrm{b}}^{\prime}=0.5+\frac{\Delta T_{\mathrm{b}}}{e^{-\tau}}$.

The error of the measured brightness temperature, $\Delta T_{\mathrm{b}}$, is given by the radiometer equation:

$\Delta T_{\mathrm{b}}=\frac{T_{\mathrm{b}}+T_{\mathrm{rec}}}{\sqrt{\Delta f \cdot t_{\mathrm{int}}}}$.

The radiometer equation gives the resolution of the radiation measured, which is determined by the bandwidth of the individual spectrometer channels $(\Delta f)$, by the integration time $\left(t_{\text {int }}\right)$, and by the total power measured by the spectrometer. A constant error of $0.5 \mathrm{~K}$ is considered as a systematic bias of the spectra, due to spectroscopic errors and the water vapour continuum. The error of the brightness temperature $\left(\Delta T_{\mathrm{b}}\right)$ is of the order of a few Kelvins in the line centre and $0.5 \mathrm{~K}$ in the line wings of the spectrum. Therefore, the measurement noise $\left(\Delta T_{\mathrm{b}}^{\prime}\right)$ depends on the bandwidth of the spectrum and on the tropospheric transmittance. This is a more realistic approach for the retrieval than considering a constant measurement noise, resulting in an improvement in the retrieved ozone VMR in the lower stratosphere. The sampling time for version 150 is $1 \mathrm{~h}$, and in the case of version 2021, it is $30 \mathrm{~min}$. Longer integration time improves the retrieved ozone VMR at upper altitudes.

A comparison between version 2021 and version 150 of ozone profiles measured by GROMOS for the time interval from July 2009 to November 2016 is displayed in Fig. 1. The mean ozone profiles retrieved by version 2021, in red, and by version 150, in blue are represented in panel (a). The SDs of the ozone VMR are shown by the coloured areas (red in the case of v2021 and blue for v150). The mean relative differences (blue line in panel (b)) and the VMR differences (blue line in panel (c)) range from $30 \%(0.5 \mathrm{ppm})$ in the lowermost stratosphere to within $5 \%(0.2 \mathrm{ppm})$ in the middle stratosphere and increase to $10 \%(0.4 \mathrm{ppm})$ in the upper stratosphere and up to $18 \%(0.05 \mathrm{ppm})$ at $0.05 \mathrm{hPa}(70 \mathrm{~km})$. The blue areas in panels (b) and (c) represent the SDs of the differences, relative differences, and VMR differences. We can conclude from Fig. 1 that the differences between version 2021 and version 150 appear in the lower stratosphere and in the mesosphere.

Figure 2 displays an example of a GROMOS retrieval accomplished by the new retrieval version 150. Panel (a) shows the a priori (green line) and the retrieved profile (blue line) measured in July 2013 at noon. The averaging kernels (AVKs) and the measurement response are represented in panel (b). The AVKs are multiplied by 4 in order to be displayed along with the measurement response (red line). The 

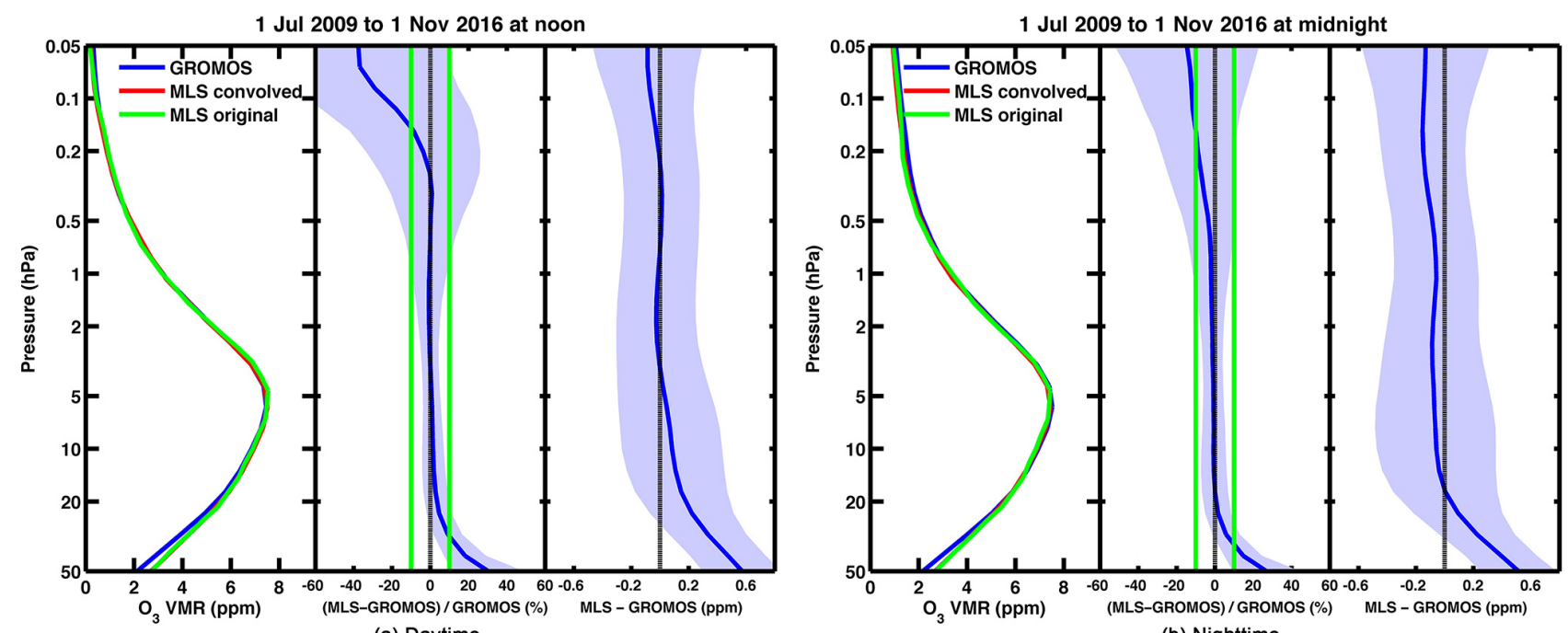

(a) Daytime

(b) Nighttime

Figure 3. Mean ozone profiles recorded by GROMOS (blue line), MLS convolved (red line), and MLS original (green line) for the time interval between July 2009 and November 2016 are shown in the left sections of both the daytime (a) and nighttime (b) panels. The blue area (GROMOS) and the red area (MLS) are the SDs of the coincident measurements. The middle sections show the mean relative difference profile between data of both instruments, with GROMOS as reference. The blue areas in the middle sections represent the SD of the differences. The green lines in the middle sections delimit the $\pm 10 \%$ area. The mean VMR difference profile and its SD (blue area) are displayed in the right-hand parts of the daytime and nighttime panels.

AVK lines are grey except for some selected altitudes, which are shown in different colours to make Fig. 2 easier to interpret. AVKs are a representation of the weighting of the information content of the retrieval parameters. The measurement response is an estimate of the a priori contribution to the retrieval and can be obtained by subtracting the area of the AVK from 1. It is considered a reliable altitude range of the retrieval when the true state dominates over the a priori information, i.e. where the measurement response is larger than 0.8 (an a priori contribution smaller than $20 \%$ ). The measurement response shown in Fig. 2 is around 1 from 18 to $70 \mathrm{~km}$. The magenta line in panel (c) shows the altitude peak of the corresponding kernels and proves that the AVK peaks at its nominal altitude for the considered altitude range. Finally, the cyan line displays the vertical resolution, which is quantified by the full width at half maximum in the averaging kernels. The vertical resolution of this new retrieval version of GROMOS lies between 10 and $15 \mathrm{~km}$ below $40 \mathrm{~km}$ altitude and between 15 and $20 \mathrm{~km}$ below $70 \mathrm{~km}$ altitude. In version 2021, the vertical resolution lies generally within $10-15 \mathrm{~km}$ in the stratosphere and increases with altitude to $20-25 \mathrm{~km}$ in the lower mesosphere. Between 20 and $52 \mathrm{~km}$ ( 50 to $0.5 \mathrm{hPa}$ ), the measurement response is higher than 0.8 . For more details on version 2021, we refer to Moreira et al. (2015). Comparing the measurement response and the vertical resolution obtained by version 2021 and by version 150 , we can conclude that there is an improvement in the results retrieved by version 150 . We assume that the changes performed in the a priori covariance matrix, in the measurement noise, and in the integration time result in the improvement of the retrieval product, mainly observed in the lowermost and in the uppermost limit of the retrieved ozone VMR profile.

For technical details and measurement principles of the instrument, see, for example, Moreira et al. (2015) and Peter (1997) and references included therein.

\subsection{The Aura Microwave Limb Sounder}

The MLS is a passive microwave limb-sounding radiometer onboard the NASA Aura satellite. The Aura spacecraft was launched in 2004 into a near polar, sun-synchronous orbit with a period of approximately $100 \mathrm{~min}$. The satellite overpasses the GROMOS measurement location (at northern midlatitudes) twice a day, approximately around noon and midnight. The standard product for ozone is derived from MLS radiance measurements near $240 \mathrm{GHz}$. The vertical resolution of the ozone profiles ranges from $3 \mathrm{~km}$ in the stratosphere to $6 \mathrm{~km}$ in the mesosphere (Schwartz et al., 2008). The present study has used ozone profiles from version 4.2. A summary of the quality of version 4.2 Aura MLS Level 2 data can be found in Livesey et al. (2017). Details about the Aura mission can be found in Waters et al. (2006).

\section{Comparison of MLS and GROMOS}

The vertical resolution of the MLS is within $3.5 \mathrm{~km}$ in the stratosphere and up to $5.5 \mathrm{~km}$ in the middle mesosphere. Therefore, in order to compare ozone profiles of GROMOS with MLS, an averaging kernel smoothing is applied to the ozone profiles of the satellite data. The smoothed profile of 

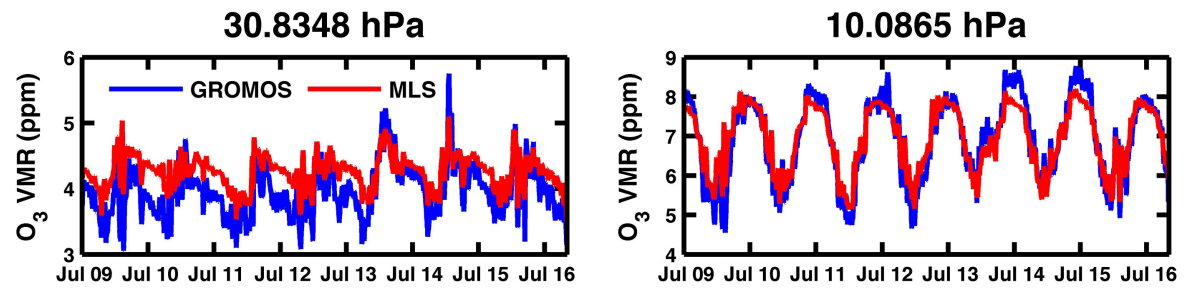

\section{$5.7688 \mathrm{hPa}$}
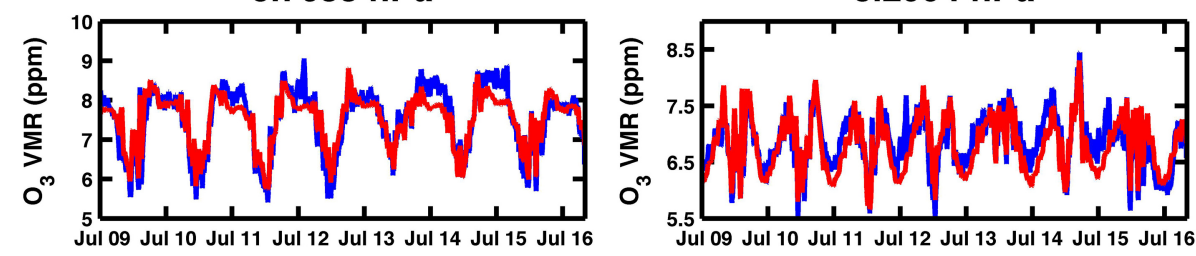

$1.0793 \mathrm{hPa}$

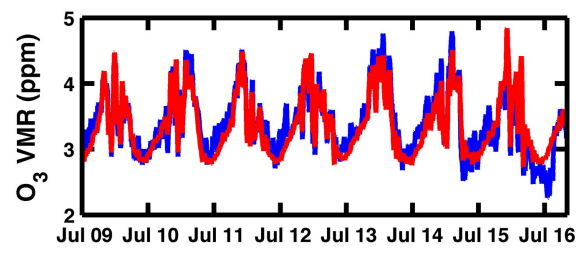

$0.61728 \mathrm{hPa}$

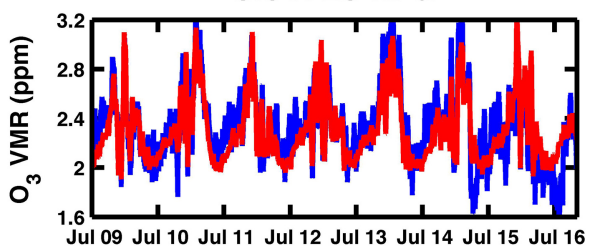

Figure 4. Time series of averaged daytime and nighttime $\mathrm{O}_{3}$ VMR measurements of GROMOS (blue line) and MLS (red line) for the period from July 2009 to November 2016 at different pressure levels. An averaging kernel smoothing has been applied to the series of the MLS measurements coincident in time and space with the GROMOS measurements. Both time series are smoothed over seven points or $\sim 1$ week in time by a moving average.
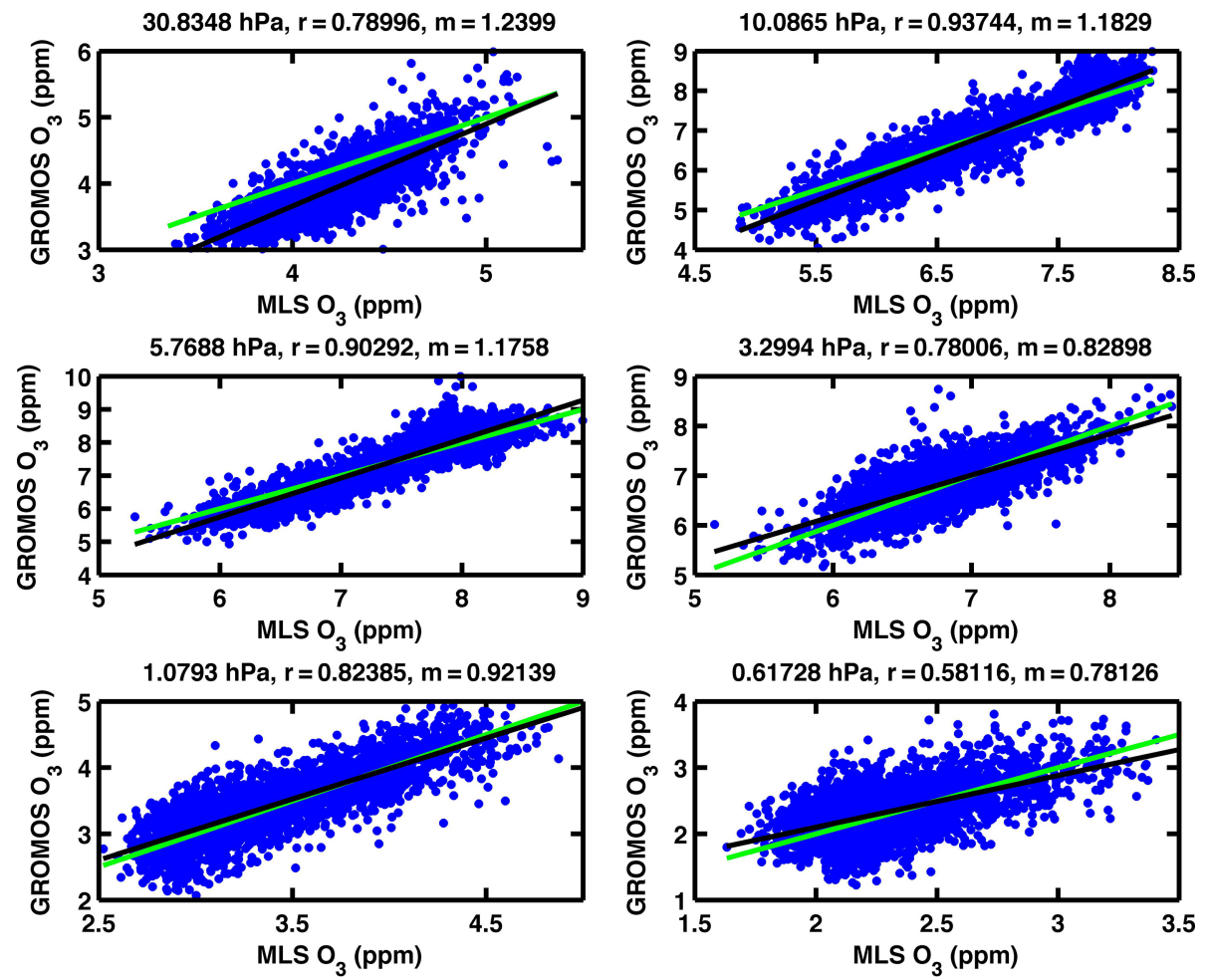

Figure 5. Scatter plots of coincident $\mathrm{O}_{3}$ VMR measurements of GROMOS and MLS for the period from July 2009 to November 2016 at different pressure levels. The black line is the linear fit of both time series, and $m$ is the slope of the linear fit. The green line indicates the case of identity, $\mathrm{O}_{3}$ (MLS) $=\mathrm{O}_{3}$ (GROMOS). $r$ values are correlation coefficients of the MLS and GROMOS time series. 
(a)
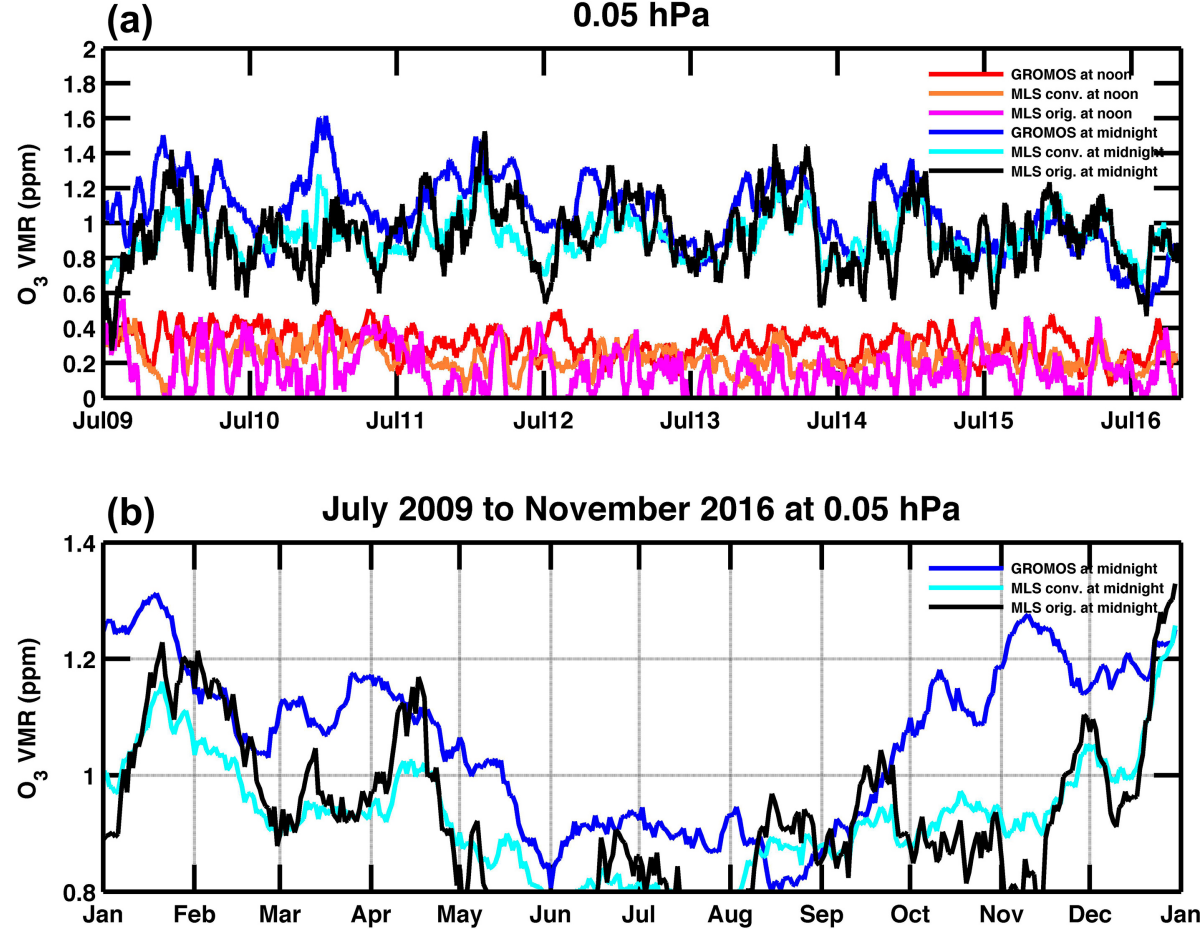

Figure 6. Panel (a) shows the diurnal variation in $\mathrm{O}_{3}$ VMR measured at noon (GROMOS in red, MLS convolved in orange, and MLS original in magenta) and at midnight (GROMOS in blue, MLS convolved in cyan, and MLS original in black) at $0.05 \mathrm{hPa}(70 \mathrm{~km})$, and panel (b) shows its evolution throughout the year averaged for the time interval under assessment (July 2009-November 2016). All time series are smoothed in time by a moving average over 15 points ( $\sim 1$ week).

MLS adjusted to the vertical resolution of GROMOS is expressed as

$\mathbf{x}_{\text {MLS,low }}=\mathbf{x}_{\mathrm{a}, \text { GROMOS }}$

$+\mathbf{A V K}_{\text {GROMOS }} \cdot\left(\mathbf{x}_{\text {MLS, high }}-\mathbf{x}_{\mathrm{a}, \text { GROMOS }}\right)$,

where $\mathbf{A V K} \mathbf{K}_{\mathrm{GROMOS}}$ is the averaging kernel matrix of

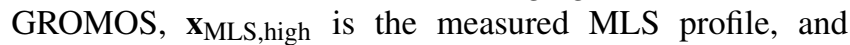
$\mathbf{x}_{\mathrm{a}, \mathrm{GROMOS}}$ is the a priori profile used during the retrieval procedure of GROMOS. The application of averaging kernel smoothing for the comparison of profiles with different altitude resolutions has been introduced and described by, e.g., Tsou et al. (1995).

Every profile utilized in the comparison between MLS and GROMOS should be coincident in time and space. The requirement of time coincidence is satisfied when both measurements are within $1 \mathrm{~h}$ in time. The selected criterion for spatial coincidence is that horizontal distances between the sounding volumes of the satellite and the ground station have to be smaller than $1^{\circ}$ in latitude and $8^{\circ}$ in longitude.

The present study extends over the period from July 2009 to November 2016 and covers the stratosphere and middle mesosphere from 50 to $0.05 \mathrm{hPa}$ (from 21 to $70 \mathrm{~km}$ ), and according to the spatial and temporal criteria, more than 2800 coincident profiles are available for the comparison. Figure $3 \mathrm{a}$ and $\mathrm{b}$ show the mean ozone profiles of the collocated and coincident measurements of GROMOS (blue line), MLS convolved (red line), and MLS original (green line) during the daytime and nighttime, respectively. The relative difference profile in percent given by $\left(\mathbf{x}_{\mathrm{MLS} \text {,low }}-\right.$ $\mathbf{x}_{\text {GROMOS }}$ )/ $\mathbf{x}_{\text {GROMOS }}$ is displayed in the middle section of both Fig. 3a and $b$ along with the SD of the differences (blue area). The green line delimits the $\pm 10 \%$ area. The mean profile of the VMR differences is shown in the right sections of both Fig. 3a and b. The mean relative differences and the VMR differences during the daytime (nighttime) are over $20 \%$ or $0.5 \mathrm{ppm}(15 \%$ or $0.4 \mathrm{ppm})$ in the lower stratosphere, decreasing with altitude to $0.7 \%$ or $0.02 \mathrm{ppm}(2 \%$ or $0.06 \mathrm{ppm})$ at the stratopause and increasing with altitude up to $38 \%$ or $0.085 \mathrm{ppm}(15 \%$ or $0.12 \mathrm{ppm})$ at $0.05 \mathrm{hPa}$ $(70 \mathrm{~km})$. We conclude from Fig. 3 that during nighttime GROMOS measures more $\mathrm{O}_{3}$ VMR (ppm) than MLS except for the lower stratosphere, where MLS measures more $\mathrm{O}_{3}$ VMR (ppm) than GROMOS, both during the daytime and nighttime. Nevertheless in the mesosphere GROMOS measures more $\mathrm{O}_{3}$ VMR (ppm) than MLS, both during the daytime and nighttime.

For an overview of the differences between coincident profiles, the average over daytime and nighttime values of the ozone VMR (ppm) time series of GROMOS (blue line) and MLS (red line) are displayed in Fig. 4 for different pressure levels. All time series have been smoothed by a moving average over seven data points ( $\sim 1$ week). The agree- 


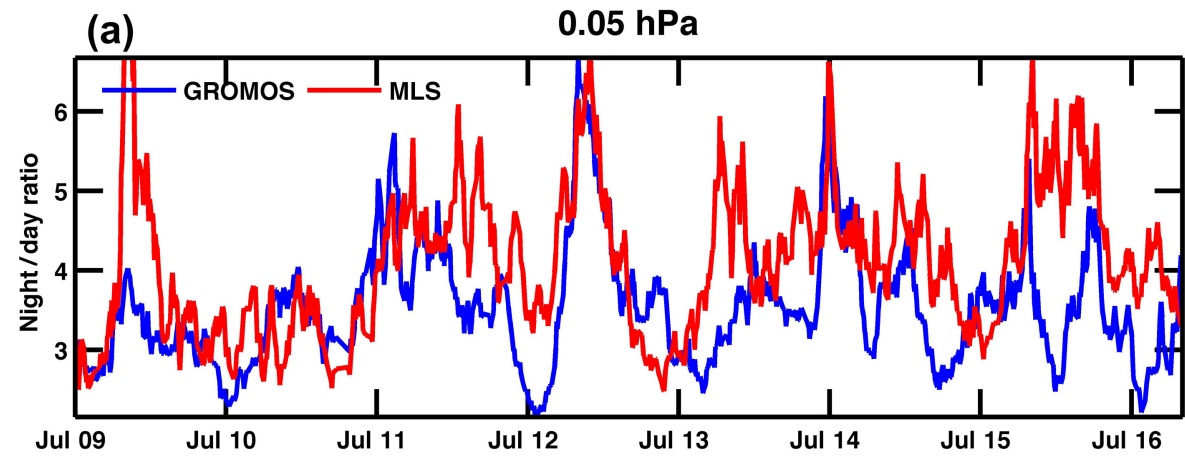

(b) July 2009 to November 2016 at $0.05 \mathrm{hPa}$

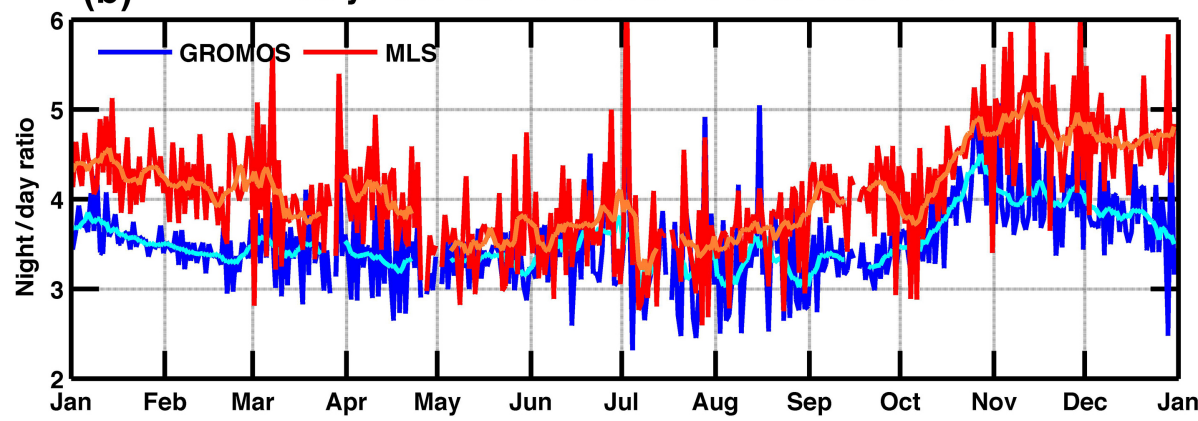

Figure 7. Panel (a) displays the night-to-day ratio (NDR) of GROMOS (blue line) and MLS (red line) at $0.05 \mathrm{hPa}(70 \mathrm{~km})$ for the time period from July 2009 to November 2016, and panel (b) shows its evolution throughout the year averaged for this time period. The time series presented in (a) are smoothed in time by a moving average over 30 data points ( 1 month), and the orange line (MLS) and the cyan line (GROMOS) shown in (b) are averaged over seven data points ( $\sim 1$ week).

ment between both ground-based and satellite-based instruments depends upon altitude and time. A negative deviation of GROMOS series with respect to MLS occurs in the lower stratosphere. On the other hand, a positive deviation of GROMOS with respect to MLS is observed in the middle stratosphere for summers 2011, 2012, 2014, and 2015. Further, we notice a negative bias of GROMOS during summer 2016 from the stratopause towards the mesosphere. The scatter plots of averaged daytime and nighttime $\mathrm{O}_{3}$ VMR measurements of GROMOS and MLS are shown in Fig. 5 at the same pressure levels as Fig. 4. The black lines, linear regression lines of the observations, are close to the green 1to-1 lines $\left(\mathrm{O}_{3}(\mathrm{MLS})=\mathrm{O}_{3}(\right.$ GROMOS $\left.)\right)$, except in the lower stratosphere, where we find the negative deviation of GROMOS with respect to MLS. The linear fit deviates from the identity where there is less ozone in the case of GROMOS during winter in the middle to upper stratosphere as we also observe in Fig. 4, along with the positive deviation of GROMOS with respect to MLS during some summers. The calculation of the correlation coefficients also reveals good agreement with $r>0.75$ for all altitude levels except for the altitude above $50 \mathrm{~km}$ where $r$ is around 0.55 .

\section{Analysis of the night-to-day ratio}

The diurnal variation in mesospheric ozone is characterized by an increase at the beginning of the nighttime and by a decrease after sunrise. This effect is explained by the recombination of atomic and molecular oxygen (e.g. Brasseur and Solomon, 2005). Because the ozone distribution in the mesosphere is mainly controlled by photochemistry, it depends strongly on the solar zenith angle (Nagahama et al., 2003); therefore, an annual variation is also expected in mesospheric ozone. Figure 6 shows both the diurnal variation in mesospheric ozone and the annual variation in nighttime mesospheric ozone. To analyse the variability in mesospheric ozone we have used ozone VMR measurements coincident in space and in time recorded by GROMOS and by MLS for the time period from July 2009 to November 2016. Fig. 6a displays the $\mathrm{O}_{3}$ VMR measured at noon (GROMOS in red, MLS convolved in orange, and MLS original in magenta) and at midnight (GROMOS in blue, MLS convolved in cyan, and MLS original in black) at $0.05 \mathrm{hPa}(70 \mathrm{~km})$ for the time period already mentioned. The original MLS data, i.e. those not weighted with GROMOS AVKs, are shown in order to provide an insight into the observability of the effect of MMM at northern midlatitudes by GROMOS. We define the average between the values recorded within $2 \mathrm{~h}$ 
around midnight (noon) as the midnight (noon) value. The daytime mesospheric ozone does not show any distinct annual variation. On the other hand, the annual variation in nighttime mesospheric ozone is characterized by a maximum in wintertime and a minimum in summertime. Fig. $6 \mathrm{~b}$ shows the evolution of the midnight mesospheric ozone throughout the year averaged for the time interval from July 2009 to November 2016. All time series displayed in both panels of Fig. 6 have been smoothed in time by a moving average over 15 data points ( $\sim 1$ week). A closer observation shows that the annual variation in the nighttime ozone exhibits a primary maximum over wintertime and a secondary maximum around springtime. Our results on the annual variation in mesospheric ozone at Bern (Switzerland, $46.95^{\circ} \mathrm{N}$, $7.44^{\circ} \mathrm{E}$ ) are in agreement with the ones observed at Lindau (Germany, 51.66 ${ }^{\circ} \mathrm{N}, 10.13^{\circ} \mathrm{E}$ ) by Sonnemann et al. (2007). Disagreements appear in the amplitudes where the maximum values of GROMOS and MLS original do not exceed 1.5, or $1.2 \mathrm{ppm}$ in the case of MLS convolved, whereas at Lindau the maximum values exceed $3 \mathrm{ppm}$ at $70 \mathrm{~km}$. Nevertheless, our results are expected since this maximum in mesospheric ozone during nighttime in winter is related to the middlemesospheric maximum in ozone (MMM), and according to Sonnemann et al. (2007), its effect extends into midlatitudes with decreasing amplitude. Furthermore, we have analysed the amplitude of the diurnal variation, the night-to-day ratio (NDR). The NDR is closely related to the MMM, but it is also related to the change in the diurnal variation from winter to summer (Sonnemann et al., 2007). The annual variation in the NDR is modulated by oscillations of a planetary timescale (Sonnemann et al., 2007). Sofieva et al. (2009) reported that during a sudden stratospheric warming event the tertiary ozone maximum can decrease significantly or can even be completely destroyed. Hocke (2017) has shown the loss of the tertiary ozone layer in the polar mesosphere due to the solar proton event in November 2004.

Fig. 7a displays the NDR of GROMOS (blue line) and MLS (red line) at $0.05 \mathrm{hPa}(70 \mathrm{~km})$ for the time interval from July 2009 to November 2016, while Fig. 7b shows its evolution throughout the year averaged for the time interval under assessment. Both time series were smoothed in time by a moving average over 30 points $(\sim 1$ month). The orange line (MLS) and the cyan line (GROMOS) depicted in Fig. 7b show a moving average over seven data points $(\sim 1$ week) with the aim of clarifying Fig. 7. Both the ground-based and the satellite-based instruments confirm the expected winter enhancement of the NDR, also observed at Lindau by Sonnemann et al. (2007), although the data from the latter exhibit larger amplitudes. We observe winter-to-summer values of a factor of 1-2, whereas at Lindau, winter-to-summer values vary by a factor of 2-3 at $70 \mathrm{~km}$ (Sonnemann et al., 2007). Thus, despite the definition of the MMM being restricted to high latitudes, we can report its observation with a smaller amplitude at midlatitudes.

\section{Conclusions}

Stratospheric and middle-mesospheric ozone profiles for the period from July 2009 to November 2016 recorded by the ground-based instrument GROMOS and by the space-based instrument MLS were used to perform a comparison and to evaluate the diurnal variability and its amplitude, the NDR. The agreement between measurements coincident in space and time for both data records is within $2 \%(0.06 \mathrm{ppm})$ between 30 and $50 \mathrm{~km}(15-0.7 \mathrm{hPa})$, increasing up to $20 \%$ $(0.5 \mathrm{ppm})$ at $20 \mathrm{~km}(50 \mathrm{hPa})$, for both daytime and nighttime. In the mesosphere the difference increases up to $38 \%$ $(0.085 \mathrm{ppm})$ during the daytime and up to $15 \%(0.12 \mathrm{ppm})$ during the nighttime at $70 \mathrm{~km}(0.05 \mathrm{hPa})$. In general terms, we report good agreement between the new retrieval version (v150) of GROMOS and the version 4.2 of MLS. Furthermore, we observe extensions of the middle-mesospheric maximum in ozone (MMM) during winter towards northern midlatitudes. This effect is smaller in amplitude at midlatitudes compared to high latitudes. Moreover, the winter enhancement of nighttime mesospheric ozone is observed by GROMOS and MLS above Bern.

Code availability. Routines for data analysis are available upon request by Lorena Moreira (lorena.moreira@iap.unibe.ch).

Data availability. The data from the GROMOS microwave radiometer is available via http://ftp.cpc.ncep.noaa.gov/ndacc/station/ bern/hdf/mwave. MLS v4.2 data are available from the NASA Goddard Space Flight Center Earth Sciences Data and Information Services Center (GES DISC): http://disc.sci.gsfc.nasa.gov/Aura/ data-holdings/MLS/index.shtml.

Author contributions. KH performed the retrieval of the GROMOS measurements. LM carried out the data analysis and prepared the paper. NK is the principal investigator of the radiometry project. All authors have contributed to the interpretation of the results.

Competing interests. All authors declare that there are no conflicts of interest.

Special issue statement. This article is part of the special issue "Twenty-five years of operations of the Network for the Detection of Atmospheric Composition Change (NDACC) (AMT/ACP/ESSD inter-journal SI)". It is not associated with a conference.

Acknowledgements. This work was supported by the Swiss National Science Foundation under Grant 200020-160048 and MeteoSwiss GAW Project: "Fundamental GAW parameters measured by microwave radiometry". 
Edited by: Hal Maring

Reviewed by: three anonymous referees

\section{References}

Brasseur, G. P. and Solomon, S.: Aeronomy of the Middle Atmosphere: Chemistry and Physics of the Stratosphere and Mesosphere, vol. 32 of Atmospheric and Oceanographic Science Library, Springer Science, the Netherlands, 2005.

Degenstein, D. A., Gattinger, R. L., Lloyd, N. D., Bourassa, A. E., Wiensz, J. T., and Llewellyn, E. J.: Observations of an extended mesospheric tertiary ozone peak, J. Atmos. Sol.-Terr. Phy., 67, 1395-1402, https://doi.org/10.1016/j.jastp.2005.06.019, 2005.

Dumitru, M., Hocke, K., Kämpfer, N., and Calisesi, Y.: Comparison and validation studies related to ground-based microwave observations of ozone in the stratosphere and mesosphere, J. Atmos. Sol.-Terr. Phy., 68, 745-756, https://doi.org/10.1016/j.jastp.2005.11.001, 2006.

Eriksson, P., Jiménez, C., and Buehler, S. A.: Qpack, a general tool for instrument simulation and retrieval work, J. Quant. Spectrosc. Ra., 91, 47-64, https://doi.org/10.1016/j.jqsrt.2004.05.050, 2005.

Eriksson, P., Buehler, S., Davis, C., Emde, C., and Lemke, O.: ARTS, the atmospheric radiative transfer simulator, version 2, J. Quant. Spectrosc. Ra., 112, 1551-1558, https://doi.org/10.1016/j.jqsrt.2011.03.001, 2011.

Fleming, E. L., Chandra, S., Barnett, J., and Corney, M.: Zonal mean temperature, pressure, zonal wind and geopotential height as functions of latitude, Adv. Space Res., 10, 11-59, https://doi.org/10.1016/0273-1177(90)90386-E, 1990.

Hartogh, P., Jarchow, C., Sonnemann, G. R., and Grygalashvyly, M.: On the spatiotemporal behavior of ozone within the upper mesosphere/mesopause region under nearly polar night conditions, J. Geophys. Res.-Atmos., 109, D18303, https://doi.org/10.1029/2004JD004576, 2004.

Hocke, K.: Response of the middle atmosphere to the geomagnetic storm of November 2004, J. Atmos. Sol.-Terr. Phy., 154, 86-91, https://doi.org/10.1016/j.jastp.2016.12.013, 2017.

Keckhut, P., Hauchecorne, A., Blanot, L., Hocke, K., GodinBeekmann, S., Bertaux, J.-L., Barrot, G., Kyrölä, E., van Gijsel, J. A. E., and Pazmino, A.: Mid-latitude ozone monitoring with the GOMOS-ENVISAT experiment version 5: the noise issue, Atmos. Chem. Phys., 10, 11839-11849, https://doi.org/10.5194/acp-10-11839-2010, 2010.

Kuntz, M.: A new implementation of the Humlicek algorithm for the calculation of the Voigt profile function, J. Quant. Spectrosc. Ra., 57, 819-824, https://doi.org/10.1016/S00224073(96)00162-8, 1997.

Livesey, N. J., Read, W. G., Wagner, P. A., Froidevaux, L., Lambert, A., Manney, G. L., Valle, L. F. M., Pumphrey, H. C., Santee, M. L., Schwartz, M. J., Wang, S., Fuller, R. A., Jarnot, R. F., Knosp, B. W., and Martinez, E.: EOS Aura-MLS Version $4.2 \times$ Level 2 data quality and description document, JPL D33509 Rev. C, https://mls.jpl.nasa.gov/data/v4-2_data_quality_ document.pdf, 2017.

Marsh, D., Smith, A., Brasseur, G., Kaufmann, M., and Grossmann, K.: The existence of a tertiary ozone maximum in the high-latitude middle mesosphere, Geophys. Res. Lett., 28, 45314534, https://doi.org/10.1029/2001GL013791, 2001.

Moreira, L., Hocke, K., Eckert, E., von Clarmann, T., and Kämpfer, N.: Trend analysis of the 20-year time series of stratospheric ozone profiles observed by the GROMOS microwave radiometer at Bern, Atmos. Chem. Phys., 15, 10999-11009, https://doi.org/10.5194/acp-15-10999-2015, 2015.

Nagahama, T., Nakane, H., Fujinuma, Y., Ogawa, H., Mizuno, A., and Fukui, Y.: A semiannual variation of ozone in the middle mesosphere observed with the millimeter-wave radiometer at Tsukuba, Japan, J. Geophys. Res.-Atmos., 108, D214684, https://doi.org/10.1029/2003JD003724, 2003.

Peter, R.: The ground-based millimeter-wave ozone spectrometerGROMOS, IAP Research Report, University of Bern, Bern, Switzerland, 1997.

Pickett, H., Poynter, R., Cohen, E., Delitsky, M., Pearson, J., and Müller, H.: Submillimeter, millimeter, and microwave spectral line catalog, J. Quant. Spectrosc. Ra., 60, 883-890, https://doi.org/10.1016/S0022-4073(98)00091-0, 1998.

Rodgers, C. D.: Retrieval of atmospheric temperature and composition from remote measurements of thermal radiation, Rev. Geophys., 14, 609-624, https://doi.org/10.1029/RG014i004p00609, 1976.

Rodgers, C. D.: Characterization and error analysis of profiles retrieved from remote sounding measurements, J. Geophys. Res.-Atmos., 95, 5587-5595, https://doi.org/10.1029/JD095iD05p05587, 1990.

Rothman, L., Rinsland, C., Goldman, A., Massie, S., Edwards, D., Flaud, J.-M., Perrin, A., Camy-Peyret, C., Dana, V., Mandin, J.-Y., Schroeder, J., McCann, A., Gamache, R., Wattson, R., Yoshino, K., Chance, K., Jucks, K., Brown, L., Nemtchinov, V., and Varanasi, P.: The hitran molecular spectroscopic database and hawks (hitran atmospheric workstation): 1996 edition, J. Quant. Spectrosc. Ra., 60, 665-710, https://doi.org/10.1016/S0022-4073(98)00078-8, 1998.

Schwartz, M. J., Lambert, A., Manney, G. L., Read, W. G., Livesey, N. J., Froidevaux, L., Ao, C. O., Bernath, P. F., Boone, C. D., Cofield, R. E., Daffer, W. H., Drouin, B. J., Fetzer, E. J., Fuller, R. A., Jarnot, R. F., Jiang, J. H., Jiang, Y. B., Knosp, B. W., Krüger, K., Li, J.-L. F., Mlynczak, M. G., Pawson, S., Russell, J. M., Santee, M. L., Snyder, W. V., Stek, P. C., Thurstans, R. P., Tompkins, A. M., Wagner, P. A., Walker, K. A., Waters, J. W., and Wu, D. L.: Validation of the Aura Microwave Limb Sounder temperature and geopotential height measurements, J. Geophys. Res.-Atmos., 113, D15S11, https://doi.org/10.1029/2007JD008783, 2008.

Sofieva, V. F., Kyrölä, E., Verronen, P. T., Seppälä, A., Tamminen, J., Marsh, D. R., Smith, A. K., Bertaux, J.-L., Hauchecorne, A., Dalaudier, F., Fussen, D., Vanhellemont, F., Fanton d'Andon, O., Barrot, G., Guirlet, M., Fehr, T., and Saavedra, L.: Spatiotemporal observations of the tertiary ozone maximum, Atmos. Chem. Phys., 9, 4439-4445, https://doi.org/10.5194/acp-9-44392009, 2009.

Sonnemann, G., Hartogh, P., Jarchow, C., Grygalashvyly, M., and Berger, U.: On the winter anomaly of the night-today ratio of ozone in the middle to upper mesosphere in middle to high latitudes, Adv. Space Res., 40, 846-854, https://doi.org/10.1016/j.asr.2007.01.039, 2007. 
Steinbrecht, W., Claude, H., Schönenborn, F., McDermid, I. S., Leblanc, T., Godin-Beekmann, S., Keckhut, P., Hauchecorne, A., Gijsel, J. A. E. V., Swart, D. P. J., Bodeker, G. E., Parrish, A., Boyd, I. S., Kämpfer, N., Hocke, K., Stolarski, R. S., Frith, S. M., Thomason, L. W., Remsberg, E. E., Savigny, C. V., Rozanov, A., and Burrows, J. P.: Ozone and temperature trends in the upper stratosphere at five stations of the Network for the Detection of Atmospheric Composition Change, Int. J. Remote Sens., 30, 3875-3886, https://doi.org/10.1080/01431160902821841, 2009.

Studer, S., Hocke, K., Pastel, M., Godin-Beekmann, S., and Kämpfer, N.: Intercomparison of stratospheric ozone profiles for the assessment of the upgraded GROMOS radiometer at Bern, Atmos. Meas. Tech. Discuss., 6, 6097-6146, https://doi.org/10.5194/amtd-6-6097-2013, 2013.

Tsou, J. J., Connor, B. J., Parrish, A., McDermid, I. S., and Chu, W. P.: Ground-based microwave monitoring of middle atmosphere ozone: comparison to lidar and Stratospheric and Gas Experiment II satellite observations, J. Geophys. Res.-Atmos., 100, 3005-3016, https://doi.org/10.1029/94JD02947, 1995.

van Gijsel, J. A. E., Swart, D. P. J., Baray, J.-L., Bencherif, H., Claude, H., Fehr, T., Godin-Beekmann, S., Hansen, G. H., Keckhut, P., Leblanc, T., McDermid, I. S., Meijer, Y. J., Nakane, H., Quel, E. J., Stebel, K., Steinbrecht, W., Strawbridge, K. B., Tatarov, B. I., and Wolfram, E. A.: GOMOS ozone profile validation using ground-based and balloon sonde measurements, Atmos. Chem. Phys., 10, 10473-10488, https://doi.org/10.5194/acp-10-10473-2010, 2010.
Waters, J. W., Froidevaux, L., Harwood, R. S., Jarnot, R. F., Pickett, H. M., Read, W. G., Siegel, P. H., Cofield, R. E., Filipiak, M. J., Flower, D. A., Holden, J. R., Lau, G. K., Livesey, N. J., Manney, G. L., Pumphrey, H. C., Santee, M. L., Wu, D. L., Cuddy, D. T., Lay, R. R., Loo, M. S., Perun, V. S., Schwartz, M. J., Stek, P. C., Thurstans, R. P., Boyles, M. A., Chandra, K. M., Chavez, M. C., Chen, G.-S., Chudasama, B. V., Dodge, R., Fuller, R. A., Girard, M. A., Jiang, J. H., Jiang, Y., Knosp, B. W., LaBelle, R. C., Lam, J. C., Lee, K. A., Miller, D., Oswald, J. E., Patel, N. C., Pukala, D. M., Quintero, O., Scaff, D. M., Snyder, W. V., Tope, M. C., Wagner, P. A., and Walch, M. J.: The Earth observing system microwave limb sounder (EOS MLS) on the aura Satellite, IEEE T. Geosci. Remote, 44, 1075-1092, https://doi.org/10.1109/TGRS.2006.873771, 2006.

WMO: Scientific Assessment of Ozone Depletion: 2014, Global Ozone Research and Monitoring Project-Report No. 55, 416 pp., Geneva, Switzerland, 2014. 